\title{
A contextualização histórica da evolução em livros didáticos de Ciências
}

\author{
Jessica Amanda Lourenço dos Santos \\ Gabriel Nardy Klein \\ Waldir Stefano \\ Rafael Cava Mori
}

\begin{abstract}
Resumo
Muitos educadores concordam que os conteúdos da educação científica escolar devam ser contextualizados historicamente. Com base nisso, este trabalho analisou a presença da contextualização histórica da teoria da evolução, nos três livros didáticos de Ciências (séries finais do ensino fundamental) mais presentes em escolas do Estado de São Paulo (2017-2019). Foram tomadas em consideração tanto discussões historiográficas sobre esses conteúdos quanto a noção de perfil conceitual sobre adaptação. $A$ análise abordou elementos textuais e imagéticos, identificando as seguintes características na abordagem de evolução nos livros: predominância de Charles Darwin entre os estudiosos mencionados; imprecisões históricas, principalmente nas exposições sobre outros naturalistas que contribuíram para a teoria evolutiva; apropriações livres, quanto a prescrições curriculares oficiais; hibridização discursiva e relativa variedade de atividades propostas; e contribuições para o fortalecimento das zonas transformacional e variacional, quanto ao perfil conceitual de adaptação, sem tentativas de deslegitimação das zonas do funcionalismo intra-orgânico e do ajuste providencial. Conclui-se que a tradição dos manuais escolares, quanto à presença da contextualização histórica nos conteúdos de evolução, permanece representada pelos livros analisados, junto de tentativas de atualizações.
\end{abstract}

Palavras-chave: Programa Nacional do Livro Didático; adaptação; ensino de ciências biológicas.

\begin{abstract}
Many educators agree that the contents of school science education should be historically contextualized. Based on this, the present article analyzed the presence of historical contextualization in the theory of evolution in three Science textbooks (final grades of primary school) most commonly found in schools in the state of São Paulo (20172019). We took into account both the historiographic discussions about these contents and the notion of conceptual profile about adaptation. Our analysis addressed textual and imagery elements, identifying the following characteristics in the way evolution is approached in the books: a predominance of Charles Darwin among the researchers mentioned; historical inaccuracies, particularly in the expositions on other naturalists who contributed to evolutionary theory; free appropriation regarding official curricular prescriptions; discursive hybridization and a relative variety of activities proposed; and contributions to the strengthening of the transformational and variational zones regarding the conceptual profile of adaptation, without attempts to delegitimize the intra-organic functionalism and providential adjustment zones. We conclude that, with regard to the presence of historical contextualization of evolution, the tradition of school textbooks is still represented by the textbooks analyzed, along with updating.
\end{abstract}

Keywords: Brazilian National Program of Textbooks; adaptation; teaching of biological sciences.

\section{INTRODUÇÃO}

Muitos educadores concordam que os conteúdos escolares, quando expostos de forma contextualizada, contribuem para a formação dos estudantes. Assim, no ensino de ciências, a apresentação do conhecimento considerando seu contexto sociopolítico, por exemplo, subsidiaria uma visão menos mitificada e ingênua sobre a construção do saber elaborado. Para que se atinja isso, alguns 
especialistas defendem conteúdos de história da ciência como parte da educação científica dos jovens. Alguns argumentos a favor dessa abordagem histórica contextual são listados por Matthews:

\begin{abstract}
[...] (1) motiva e atrai os alunos; (2) humaniza a matéria; (3) promove uma compreensão melhor dos conceitos científicos por traçar seu desenvolvimento e aperfeiçoamento; (4) há um valor intrínseco em se compreender certos episódios fundamentais na história da ciência - a Revolução científica, o darwinismo, etc.; (5) demonstra que a ciência é mutável e instável e que, por isso, o pensamento científico atual está sujeito a transformações que (6) se opõem a ideologia cientificista; e, finalmente, (7) a história permite uma compreensão mais profícua do método científico e apresenta os padrões de metodologia vigente.
\end{abstract}

É interessante notar que tal recurso para um ensino mais contextualizado não é especificado pela legislação brasileira. Quando mencionado, por exemplo, nos Parâmetros Curriculares Nacionais (PCN), é a partir de comentários gerais, ou subsumido a outros aspectos da educação científica, como a questão das concepções alternativas dos estudantes:

[...] conhecimentos dos estudantes, que anteriormente não eram levados em conta no contexto escolar, passaram a ser objeto de particular atenção e recomendações. $A$ História da Ciência tem sido útil nessa proposta de ensino, pois o conhecimento das teorias do passado pode ajudar a compreender as concepções dos estudantes do presente, além de também constituir conteúdo relevante de aprendizado².

Assim, inexiste uma base comum de conteúdos de história da ciência a permear as disciplinas da educação básica. Dessa maneira, os professores dispõem de liberdade para escolher as abordagens que julgarem melhor favorecer a contextualização histórica, de modo a promover um ensino de ciências mais humanizado e articulado com a dinâmica social.

Diversos estudos defendem - e problematizam - a contextualização histórica no ensino de ciências $3,4,5,6$. Com base nessas discussões, este trabalho toma a seguinte questão de pesquisa: como os

\footnotetext{
1 Michael S. Matthews, "História, Filosofia e Ensino de Ciências: A Tendência Atual de Reaproximação." Caderno Brasileiro de Ensino de Física 12, no 3 (1995): 172-73.

2 Brasil, Parâmetros Curriculares Nacionais: Ciências Naturais (Brasília: MEC/SEF, 1998), 21.

${ }^{3}$ Rosana P. Batista, Adriana Mohr \& Nadir Ferrari, "Análise da História da Ciência em Livros Didáticos do Ensino Fundamental em Santa Catarina," in: Anais do VI Encontro Nacional de Pesquisa em Educação em Ciências (Belo Horizonte: Abrapec, 2007), não paginado.
} 
livros didáticos da educação básica apresentam a contextualização histórica no ensino de evolução? A partir dessa questão, propõe-se como objetivo analisar a presença da contextualização histórica entre conteúdos sobre evolução, em livros didáticos de Ciências para as séries finais do ensino fundamental, valendo-se da teoria dos perfis conceituais como referencial teórico - o qual será detalhado na próxima seção. A pesquisa se justifica pelo seguinte entendimento: o de que a abordagem histórica pode contribuir também para a própria elaboração do conceito de evolução pelos estudantes, articulando o ensino de ciências biológicas a diferentes saberes, disciplinas e habilidades.

Assim, antes de descrever os procedimentos metodológicos empregados e de apresentar resultados, revisemos aspectos do ensino de evolução, bem como as contribuições da teoria dos perfis conceituais para esse ensino.

\section{O ENSINO DE EVOLUÇÃO NA EDUCAÇÃO BÁSICA}

A compreensão dos processos evolutivos é central para a conceituação dos temas de biologia ${ }^{7,8}$. Por outro lado, o ensino desse conteúdo tende a levar aos estudantes uma visão rígida e idealizada sobre o desenvolvimento de tais conceitos $^{9}$ - um quadro que seria preciso alterar, caso se queira que os aprendizes desenvolvam um real entendimento da teoria evolutiva ${ }^{10}$.

A abordagem descontextualizada favorece imprecisões conceituais que necessitam ser desconstruídas. Por exemplo, o trabalho do naturalista francês Jean-Baptiste de Lamarck (1744-1829) é resumido à ideia "da lei do uso e desuso", cuja autoria é erroneamente atribuída a ele. Segundo Martins ${ }^{11}$, tal ideia vinha sendo aceita desde a Antiguidade e influenciou o próprio Charles Darwin (1809-1882). Ideias próprias de Lamarck, como suas contribuições aos campos da botânica e da sistemática, além da

\footnotetext{
4 Nélio M. V. Bizzo, "Ensino de evolução e história do darwinismo" (tese de doutorado, Universidade de São Paulo, 1991).

5 Maria E. B. Prestes \& Ana M. A. Caldeira, "Introdução. A Importância da História da Ciência na Educação Científica." Filosofia e História da Biologia 4 (2009): 1-16.

${ }^{6}$ Clarete P. Silva et al., "Subsídios para o Uso da História das Ciências no Ensino: Exemplos Extraídos das Geociências." Ciência \& Educação 14, no 3 (2008): 497-517.

7 Argus V. de Almeida, "A estrutura histórico-conceitual dos programas de pesquisa de Lamarck e Darwin e os processos de conceitualização da biologia evolutiva" (tese de doutorado, Universidade Federal de Pernambuco, 2007).

8 Claudia Sepulveda, Eduardo F. Mortimer \& Charbel N. El-Hani, "Construção de um Perfil Conceitual de Adaptação: Implicações Metodológicas para o Programa de Pesquisa Sobre Perfis Conceituais e o Ensino de Evolução." Investigações em Ensino de Ciências 18, no 2 (2013): p. 439-79.

${ }^{9}$ Argus V. de Almeida \& Jorge T. R. Falcão, "As Teorias de Lamarck e Darwin nos Livros Didáticos de Biologia no Brasil." Ciência \& Educação 16, no 3 (2010): 649-65.

10 Nélio M. V. Bizzo \& Charbel N. El-Hani, "O Arranjo Curricular do Ensino de Evolução e as Relações Entre os Trabalhos de Charles Darwin e Gregor Mendel." Filosofia e História da Biologia 4 (2009): 23557.

11 Lilian Al-Chueyr P. Martins, "Lamarck e as Quatro Leis da Variação das Espécies." Epistéme: Filosofia e História das Ciências em Revista 2, no 3 (1997): 33-54.
} 
criação do termo "biologia", acabam não sendo mencionadas - basta conferir a tradição dos livros escolares de biologia12.

Essa falta de historicidade na abordagem escolar da evolução, ou sua presença em formas equivocadas, acomete não apenas as contribuições de Lamarck. A teoria de Darwin também costuma ser apresentada sem consideração a seus aspectos originais, e o caráter controvertido das proposições darwinianas é escamoteado - confirmando a percepção de Kuhn ${ }^{13}$ de que o ensino escolar dissimula revoluções científicas, suprimindo as polêmicas geradas quando um novo paradigma se insurge contra 0 paradigma vigente. Almeida e Falcão ${ }^{14}$ relatam um desses aspectos: 0 autor de $A$ origem das espécies utilizara como argumentos, para explicar a seleção natural, fatos relativos à seleção artificial, empregada por criadores de animais e plantas para produzir novas variedades. Estas seriam como que espécies nascentes, no raciocínio analógico do naturalista inglês, o que fora contestado por Fleming Jenkin (18331885). Considerado pelo próprio Darwin como um de seus mais perspicazes oponentes, Jenkin obrigou a realização de remanejamentos e a criação de hipóteses auxiliares na embrionária teoria darwinista da evolução. No entanto, tais nuances não constam na abordagem escolar dessa teoria, reforçando a percepção sobre Darwin enquanto pensador inquestionável, ao contrário de Lamarck ${ }^{15}$.

Indo além do diagnóstico de erros conceituais veiculados na tradição escolar, Sepulveda, Mortimer e El-Hani16 estabeleceram um perfil para o conceito de adaptação, crucial para o entendimento da evolução biológica. Nessa perspectiva teórica, a aprendizagem não é tida como produto de uma mudança conceitual - 0 abandono de concepções errôneas em favor de conceitos aceitos cientificamente -, mas como resultante da reorganização das zonas que compõem um dado perfil. As zonas são entendidas como maneiras de pensar, sobre os conceitos científicos, mais ou menos típicas de determinados contextos. No caso do conceito de adaptação, os autores identificaram essas zonas recorrendo a dados diversos, que incluem a pesquisa sobre concepções alternativas e fontes da história da ciência. Foram identificadas quatro zonas principais para o conceito:

- Funcionalismo intra-orgânico: os traços adaptativos não são compreendidos como decorrentes de processos evolutivos, atendendo a finalidades e funções específicas dos seres vivos, relacionadas a seus hábitos;

\footnotetext{
12 Almeida \& Falcão, "As Teorias de Lamarck e Darwin".

13 Thomas S. Kuhn, A Estrutura das Revoluções Científicas, trad. Beatriz Vianna Boeira \& Nelson Boeira, 9 a ed. (São Paulo: Perspectiva, 2007).

14 Argus V. de Almeida \& Jorge T. R. Falcão, "A Estrutura Histórico-Conceitual dos Programas de Pesquisa de Darwin e Lamarck e sua Transposição para o Ambiente Escolar." Ciência \& Educação 11, no 1 (2005): 17-32.

15 Almeida \& Falcão, "As Teorias de Lamarck e Darwin".

16 Sepulveda, Mortimer \& El-Hani.
} 
- Ajuste providencial: considera-se que os seres possuem adaptações às condições que os circundam, harmonizando-se com elas;

- Perspectiva transformacional: diferentemente das zonas anteriores, aqui se considera a historicidade das adaptações, que são compreendidas como um ajuste filogenético ótimo, dos indivíduos às suas condições circundantes, acumulado ontogeneticamente;

- Perspectiva variacional: é a zona em que, finalmente, se considera a existência de pressões seletivas capazes de fixar, ao longo do tempo, determinadas características variantes de uma população.

Na visão de Sepulveda, Mortimer e El-Hani17, o objetivo da educação escolar seria favorecer a zona referente à perspectiva variacional, já que ela se associa a compromissos ontológicos e epistemológicos típicos das explicações darwinistas. As demais zonas, especialmente funcionalismo intraorgânico e ajuste providencial, são mais típicas do senso comum, não se esperando que a escola as reforce - embora não se nutra a expectativa de que o ensino escolar as deslegitime, enfraqueça ou elimine, o que seria um retrocesso em direção ao malogrado modelo de mudança conceitual.

Em resumo, o tema da evolução é mais rico e complexo do que a tradição do ensino escolar tende a reconhecer; as visões lamarckista e darwiniana não são tão opostas quanto a historiografia utilizada nos manuais escolares faz parecer, havendo contribuições de muitos estudiosos (inclusive do próprio Lamarck) na conformação da teoria da seleção natural; e por fim, o conceito de adaptação, além de possuir uma historicidade própria, deve ser abordado de forma a fortalecer uma visão também histórica e relacional sobre a forma como os seres orgânicos se modificam para dar origem a novas espécies.

\section{Metodologia}

Os livros didáticos são uma das principais fontes de consulta e pesquisa dentro e fora do ambiente escolar ${ }^{18}$. Além disso, no exercício de sua função referencial ${ }^{19}$, atuam como suportes materiais do currículo escolar, documentando quais conhecimentos e habilidades os setores dirigentes da sociedade consideram mais relevantes para a transmissão geracional.

Desde 1985, as escolas públicas brasileiras podem receber livros, adquiridos pelo Ministério da Educação, por meio do Programa Nacional do Livro Didático (PNLD). Desde meados dos anos 1990, execução desse programa compreende uma etapa prévia à aquisição governamental dos livros, em que

\footnotetext{
17 Ibid.

18 Hilário Fracalanza \& Jorge Megid Neto, orgs., O Livro Didático de Ciências no Brasil (Campinas: Komedi, 2006).

19 Alain Choppin, "História dos Livros e das Edições Didáticas: Sobre o Estado da Arte." Educação e Pesquisa 30, no 3 (2004): 549-566.
} 
as coleções candidatas à distribuição escolar são avaliadas por especialistas pertencentes a universidades e secretarias de educação. As obras aprovadas nesse processo avaliativo e, portanto, passíveis de alcançarem o público escolar, são resenhadas numa publicação intitulada Guia de livros didáticos. Cada Guia, divulgado ao final da avaliação de livros pelos especialistas, explicita os critérios por meio dos quais as coleções foram analisadas. No que tange aos livros investigados no presente trabalho, vejamos o que o respectivo Guia do componente curricular Ciências, séries finais do ensino fundamental, comenta sobre a contextualização histórica dos conteúdos:

Ao trabalhar com o ensino de Ciências, é importante considerarmos a história da ciência, e esta não se restringe a pontuar alguns cientistas bem-sucedidos e o contexto de suas pesquisas. A história da ciência narrada nos livros didáticos, na maioria das coleções aprovadas, é apresentada em um movimento ascendente, com ênfase nos progressos da atividade científica ${ }^{20}$.

Esta pesquisa se propõe a analisar livros presentes nesse Guia, do ano de 2017. Considerando que essas obras já passaram pelo crivo de avaliadores durante a execução do PNLD, apresentaremos uma análise com maior grau de detalhamento, buscando conhecer as principais representações, de nosso objeto de estudo, veiculadas nesses livros. Nesse aspecto, não estamos preocupados em apontar indicadores quantitativos acerca da presença ou ausência de determinadas categorias, mas em conhecer os principais conteúdos históricos propagados por esses livros na abordagem do tema evolução.

Esse tipo de estudo pode focar em aspectos textuais ou iconográficos. Batista, Mohr e Ferrari21 propuseram um instrumento de análise de conteúdos históricos em livros de Ciências cujos descritores abrangem: perfil dos personagens históricos apresentados nos livros, aspectos da produção do conhecimento, presença de ilustrações que remetam a temas históricos, tipos de contextualização aliados à contextualização histórica, proposta de atividades com conteúdos de história da ciência e tipo/propósito da abordagem histórica utilizada no livro. Aqui, empregaremos uma versão adaptada desse instrumento, 0 que será detalhado na próxima seção.

Com relação ao corpus analítico, como a pesquisa não pretende traçar um quadro exaustivo sobre seus objetos, optou-se pela análise de uma amostra dos livros de Ciências indicados pelo PNLD/2017. Essa edição do programa indicou 13 coleções a serem escolhidas pelas escolas brasileiras para o uso no triênio 2017-2019, explicitadas na Tabela 1.

\footnotetext{
20 Brasil, PNLD 2017: Ciências - Ensino Fundamental - Anos Finais (Brasília: MEC/SEB, 2016).

${ }^{21}$ Batista, Mohr \& Ferrari.
} 
Tabela 1: Obras do PNLD/2017-Ciências e suas presenças em escolas do Estado de SP. Fonte: elaboração dos autores, com base em informações do Centro de Ensino Fundamental dos Anos Finais, Coordenadoria de Gestão da Educação Básica, Secretaria Estadual da Educação-SP.

\begin{tabular}{|c|c|c|c|}
\hline \multirow{2}{*}{ editora } & \multirow{2}{*}{ título da obra } & \multicolumn{2}{|c|}{ escolas } \\
\hline & & quantidade & $\%$ \\
\hline Moderna & Projeto Araribá: Ciências & 1239 & 33,0 \\
\hline Ática & Projeto Teláris: Ciências & 481 & 12,8 \\
\hline Moderna & Ciências naturais: aprendendo com o cotidiano & 458 & 12,2 \\
\hline Saraiva & Investigar e conhecer: Ciências da Natureza & 350 & 9,3 \\
\hline Saraiva & Companhia das Ciências & 295 & 7,9 \\
\hline Brasil & Projeto Apoema: Ciências & 181 & 4,8 \\
\hline SM & Para viver juntos: Ciências da Natureza & 171 & 4,6 \\
\hline FTD & Ciências Novo Pensar & 160 & 4,3 \\
\hline Quinteto & Ciências & 158 & 4,2 \\
\hline Brasil & Tempo de Ciências & 130 & 3,5 \\
\hline Ática & Ciências & 94 & 2,5 \\
\hline SM & Universos: Ciências da Natureza & 40 & 1,1 \\
\hline Saraiva & Jornadas.cie: Ciências & - & - \\
\hline & & 3757 & 100 \\
\hline
\end{tabular}

Com base nos indicadores da Tabela 1, decidimos constituir nosso corpus com as três coleções de livros mais presentes nas séries finais do ensino fundamental brasileiro:

- Coleção 1: Projeto Araribá: Ciências22;

- Coleção 2: Projeto Teláris: Ciências³;

- Coleção 3: Ciências naturais: aprendendo com o cotidiano24.

Essas coleções, produzidas por duas editoras, perfazem $58 \%$ dos livros escolhidos pelas escolas paulistas no PNLD/2017-Ciências. Isso confirma dados que indicam, há tempos, a concentração das escolhas dos professores em títulos representativos de cada vez menos editoras $25,26,27$.

\section{ANÁLISE DAS OBRAS}

Verificou-se que os conteúdos de evolução estão concentrados nos volumes destinados ao $7^{\circ}$ ano do ensino fundamental, em conformidade com outros estudos sobre o manual escolar brasileiro de Ciências. Essas pesquisas diagnosticam certa padronização na editoração dessas obras, que raramente

\footnotetext{
22 Maíra R. Carnelille, org., Projeto Araribá: Ciências, 4a ed. (São Paulo: Moderna, 2014).

23 Fernando Gewandsznajder, Projeto Teláris: Ciências, 2a ed. (São Paulo: Ática, 2015).

24 Eduardo L. do Canto, Ciências Naturais: Aprendendo com o Cotidiano, 5 a ed. (São Paulo: Moderna, 2015).

25 Célia Cristina de Figueiredo Cassiano, O Mercado do Livro Didático no Brasil do Século XXI: A Entrada do Capital Espanhol na Educação Nacional (São Paulo: Unesp, 2013).

${ }^{26}$ Fracalanza \& Megid Neto.

27 Nilson Marcos Dias Garcia, org., O Livro Didático de Física e de Ciências em Foco: Dez Anos de Pesquisa (São Paulo: Livraria da Física, 2017).
} 
ousam superar o currículo clássico: $6^{\circ}$ ano - geociências, $7^{\circ}$ ano - seres vivos, $8^{\circ}$ ano - corpo humano/saúde, $9^{\circ}$ ano - física/química28,29,30.

Os resultados da análise das obras, conforme os descritores de Batista, Mohr e Ferrari31, estão sumarizados no Quadro 1.

Quadro 1: características da contextualização histórica, quanto ao tema evolução, nas obras do PNLD/2017 analisadas. Legenda: $\bigcirc$ Lamarck, Darwin, W Wallace, $\bigcirc$ Lyell, $\checkmark$ presença, $X$ ausência. Obras: 1) Projeto Araribá: Ciências; 2) Projeto Teláris: Ciências; 3) Ciências naturais: Aprendendo com o cotidiano. Fonte: dados da pesquisa.

\begin{tabular}{|c|c|c|c|c|}
\hline \multirow{2}{*}{ Descritor } & \multirow{2}{*}{ Categoria } & \multicolumn{3}{|c|}{ Obra } \\
\hline & & 1 & 2 & 3 \\
\hline \multirow{3}{*}{ Dados biográficos } & Contextualização temporal & 0000 & 000 & 00 \\
\hline & Contextualização geográfica & $\bullet \circ$ & $\bullet$ & - \\
\hline & Período de dedicação & 00 & 0 & 00 \\
\hline \multirow{4}{*}{ llustrações } & Cientistas & 000 & $x$ & 0 \\
\hline & Experimentos & 0 & $x$ & $x$ \\
\hline & Modelos & - & $x$ & $x$ \\
\hline & Modelos no cotidiano & 0 & 0 & O \\
\hline \multirow{5}{*}{ Atividades propostas } & Leitura no próprio livro & $\checkmark$ & $\checkmark$ & $\checkmark$ \\
\hline & Leitura em outras fontes & $\checkmark$ & $x$ & $\checkmark$ \\
\hline & Pesquisa bibliográfica & $x$ & $x$ & $\checkmark$ \\
\hline & Análise de dados históricos & $\checkmark$ & $x$ & $\checkmark$ \\
\hline & Experimentos históricos & $\checkmark$ & $\checkmark$ & $\checkmark$ \\
\hline
\end{tabular}

Esta seção discutirá os resultados a partir de três descritores gerais, que não espelham exatamente a exposição dos dados no Quadro 1: perfis dos cientistas mencionados, ilustrações e formas/funções da contextualização e das atividades. Para cada um deles, será dedicada uma subseção.

\section{Perfis dos Cientistas mencionados}

A análise dos livros verificou a presença de quatro naturalistas associados a teorias evolutivas além de Lamarck e Darwin, Alfred Wallace (1823-1913) e Charles Lyell (1797-1875).

O Quadro 1 apresenta quais tipos de dados biográficos desses estudiosos foram veiculados nos livros: a contextualização temporal compreende menções a datas de nascimento e falecimento ou, ao menos, a datas-chaves relativas à divulgação de suas principais ideias; a contextualização geográfica

\footnotetext{
28 Fracalanza \& Megid Neto.

29 Garcia.

30 Vilmarise Bobato Gramowski, Nadir Castilho Delizoicov \& Sylvia Regina Pedrosa Maestrelli, "O PNLD e os Guias dos Livros Didáticos de Ciências (1999-2014): Uma Análise Possível." Ensaio: Pesquisa em Educação em Ciências 19 (2017): 1-18.

31 Batista, Mohr \& Ferrari.
} 
abrange menções a local de nascimento e/ou local de desenvolvimento de seus trabalhos; e o período de atuação demarca cronologicamente a atuação dos cientistas no desenvolvimento das suas teorias.

Conforme o Quadro 1, apenas a obra 1 menciona o geólogo Charles Lyell e, mesmo assim, restringe-se à apresentação de suas datas de nascimento e falecimento, sem detalhar suas contribuições ao conceito de evolução. Já Wallace é mencionado nas obras 1 e 2, que situam espaço-temporalmente suas contribuições à evolução e ressaltam seu diálogo com Darwin. Este, por sinal, é o naturalista mais presente nas três obras analisadas, contemplando todas as categorias do descritor dados biográficos. A obra 1, por exemplo, dedica uma seção ("Pensar ciência") para expor da formação acadêmica de Darwin aos interesses de pesquisa que o encaminharam aos estudos naturalistas. A seção descreve também as instituições de ensino por que Darwin passou, menciona os anos de observações a bordo do Beagle, elenca suas principais publicações e relata sua amizade com outros pesquisadores. Porém, tal empenho se limita a Darwin; a mesma obra, por exemplo, identifica Lamarck imprecisamente como paleontólogo.

Essa predominância do autor de $A$ origem das espécies na abordagem histórica da evolução é uma constante na literatura biológica escolar. Almeida e Falcão ${ }^{32}$, analisando livros brasileiros da disciplina de Biologia publicados entre 1940 e 2006, mostram que a área textual dedicada a Darwin é, em média, 1,5 vezes maior que a área dispensada a Lamarck - embora haja livros que concedem mais espaço às ideias lamarckistas que as darwinianas.

Caracterizemos, abaixo, a abordagem de cada uma das obras quanto à produção de conhecimentos por parte dos cientistas.

A obra 1, ao falar de Lamarck, não traz informações cronológicas sobre seus estudos. São descritas duas das quatro leis que defendeu em sua produção científica, a "lei do uso e desuso" e a "lei de transmissão de caracteres adquiridos"33. Quanto às contribuições dos demais naturalistas, o enfoque é maior sobre Darwin. Menciona-se sua amizade com Lyell, sem que se informe a influência do geólogo em seus estudos - especialmente no que tange à hipótese auxiliar do gradualismo contínuo ${ }^{34}$-, e seus trabalhos são comparados com aqueles de Wallace.

Já a obra 2, antes do conteúdo sobre evolução, apresenta ideias sobre paleontologia e genética, sem elencar pesquisadores ou épocas em que foram conduzidos tais estudos. As noções de genética são mobilizadas para explicar a diversidade dos fósseis, abordagem que, embora imprecisa em termos historiográficos, pode ser facilitadora da aprendizagem de evolução e consolidar a zona variacional do

\footnotetext{
32 Almeida \& Falcão, "As Teorias de Lamarck e Darwin".

33 Os trabalhos de Lamarck referentes às quatro leis da variação das espécies são descritos em Martins (1997).

34 Almeida \& Falcão, "A Estrutura Histórico-Conceitual".
} 
perfil conceitual de adaptação. Segundo Almeida e Falcão ${ }^{35}$, ainda há controvérsias, entre historiadores da ciência, acerca da influência das ideias de Gregor Mendel (1822-1884) sobre os formuladores das teorias evolutivas, especialmente sobre Darwin. Nessa coleção 2, os conceitos de evolução se iniciam com uma comparação entre os trabalhos de Darwin e Wallace. Páginas à frente, num texto complementar, mencionam-se os estudos de Lamarck - e como na obra 1, citam-se duas de suas leis.

Finalmente, a obra 3 inicia o assunto com uma introdução à paleontologia, sugerindo duas hipóteses explicativas dos processos evolutivos: a primeira lei de Lamarck, resumida em três linhas, junto da advertência de que "não é aceita atualmente pelos cientistas"36; e os trabalhos de Darwin, com foco no conceito de seleção natural.

As três obras avaliadas, de forma geral, tendem a dicotomizar as contribuições de Lamarck e de Darwin, em detrimento de sua complementaridade à época em que floresceram. A prioridade em expor e enaltecer as ideias de Darwin pode contribuir para uma visão mítica, heroica e individualista da atividade científica. Nenhuma das obras menciona a importância da teoria de Lamarck para os estudos de Darwin, nem que este chegou a defender e testar as ideias lamarckistas. Assim, as obras mantêm a tradição dos manuais escolares de conhecimentos biológicos, conforme as análises de Almeida e Falcão ${ }^{37}$.

Chama a atenção que os livros não tenham atribuído tanta importância aos trabalhos de Lyell e sua frequente correspondência com Darwin. Esse diálogo entre os dois cientistas fora destacado, há cerca de 20 anos, nos próprios PCN:

Lyell (século XIX) leva adiante a teorização acerca da crosta terrestre, entendida como camadas geológicas de diferentes idades, contribuindo para a concepção de que os ambientes da Terra se formaram por uma evolução contínua atuando por longos períodos de tempo. Inspirado também pela geologia de Lyell, Charles Darwin elaborou uma teoria da evolução que possibilitou uma interpretação geral para o fenômeno da diversidade da vida, fundada nos conceitos de adaptação e seleção natural. Sua teoria levava em consideração conhecimentos de Geologia, Botânica, Zoologia, Paleontologia e Embriologia, e muitos dados colhidos em diferentes regiões do mundo ${ }^{38}$.

Por outro lado, a presença dos nomes de Lyell e Wallace (respectivamente, em uma e em duas coleções) indica a renovação da abordagem histórica e a apropriação (adaptada ou relida) de orientações

\footnotetext{
35 Almeida \& Falcão, "As Teorias de Lamarck e Darwin".

36 Canto, 63.

37 Almeida \& Falcão, "As Teorias de Lamarck e Darwin".

38 Brasil, Parâmetros Curriculares Nacionais, 25.
} 
oficiais, como evidenciado no fragmento acima. Tais apropriações livres ou releituras das prescrições curriculares são mencionadas em diversos estudos e antologias sobre o livro escolar brasileiro 39,40,41,42.

\section{ILUSTRAÇÕES}

O Quadro 1 sumariza as relações entre as ilustrações presentes nos livros e os trabalhos dos naturalistas mencionados na subseção anterior. Nesse descritor constam as categorias cientistas, experimentos, modelos e modelos no cotidiano. As três últimas, propostas por Batista, Mohr e Ferrari43 para tratar de conteúdos de história da ciência em geral, foram aqui adaptadas para a especificidade do tema evolução. Evidencia-se a ausência de ilustrações relacionadas a Lyell e a onipresença de Darwin, quanto a esse descritor.

Nas coleções 1 e 3, são ilustradas as rotas percorridas por Darwin a bordo do navio Beagle, destacando as paradas na América do Sul e em Galápagos. Na coleção 1, o tratamento desses fatos é acompanhado de outras ilustrações. Há figuras sobre evidências observacionais coletadas por Darwin, relacionadas à diversidade de tartarugas e suas adaptações de acordo com aspectos biogeográficos da região do arquipélago. A mesma coleção compara a morfologia de bicos de aves com seus hábitos alimentares, conforme relatos de Darwin. Assim, as ilustrações agenciam as observações naturalísticas darwinianas com a formulação de hipóteses para a teoria da seleção natural, veiculando ilustrações que se associam à categoria experimentos. Já a categoria modelos no cotidiano está contemplada em figuras que comparam seleção natural e artificial, com vários exemplos: as raças de cães desenvolvidas por criadores, os perigos do uso inadequado de antibióticos e a recomendação, ao professor, de que comente e problematize o uso de agrotóxicos na agricultura moderna. Assim, a coleção 1 se mostrou a mais diversificada quanto aos conteúdos ligados a problemas biotecnológicos. Por fim, nessa coleção constam também imagens relacionadas aos seguintes conceitos, consideradas pertencentes à categoria modelos: isolamento geográfico e especiação, registros fósseis, fossilização e órgãos homólogos em mamíferos.

A coleção 2, a menos ilustrada, não contemplou as categorias cientistas, experimentos e modelos. A categoria modelos no cotidiano foi contemplada ilustrando-se as pressões seletivas exercidas por inseticidas sobre baratas - o que, diferentemente da coleção 1, é considerado como exemplo de

\footnotetext{
39 Cassiano.

40 Fracalanza \& Megid Neto.

41 Garcia.

42 Isabel Martins, Guaracira Gouvêa \& Rita Vilanova, orgs., O Livro Didático de Ciências: Contextos de Exigência, Critérios de Seleção, Práticas de Leitura e Uso em Sala de Aula (Rio de Janeiro: s.ed., 2012).

43 Batista, Mohr \& Ferrari.
} 
seleção natural, e não artificial - e a apresentação de uma história em quadrinhos (HQ) relacionada à paleontologia, numa atividade proposta.

A categoria modelos no cotidiano, por meio de uma ilustração comparando os processos de seleção natural e artificial, também esteve presente na coleção 3. 0 texto que compõe a figura traz explicações sobre ideias darwinistas. O processo de surgimento de novas espécies também é ilustrado e, como na coleção 2, houve a presença de $\mathrm{HQs}$ - mais frequentemente, em três ocasiões.

Especificamente sobre as HQs, Kamel e de La Roque ${ }^{44}$ consideram que os autores de livros "utilizam este meio de comunicação de massa com o intuito de enriquecer e diversificar o material didático, procurando trazer para o contexto formal de sala de aula materiais que fazem parte do contexto sociocultural dos estudantes". De fato, diversas pesquisas mencionam que os atuais livros escolares brasileiros, também por conta das exigências do PNLD, vêm se tornando materiais cada vez mais hibridizados discursivamente, organizando seus conteúdos não apenas a partir do discurso científico de referência, mas recorrendo também a outros gêneros textuais ${ }^{45}$. Os livros investigados no presente trabalho, quanto a esse aspecto, não são exceção.

Assim, as ilustrações, nas três coleções, podem contribuir para consolidar as zonas transformacional e variacional do perfil conceitual de adaptação. Especificamente, aquelas relacionadas a modelos no cotidiano procuram relacionar as características fenotípicas dos seres a sua historicidade filogenética, considerando pressões seletivas naturais ou artificiais e evidências paleontológicas.

Ainda, verificou-se que a maior parte das ilustrações diz respeito a Darwin e suas contribuições, concordando com os resultados de Almeida e Falcão46 quanto à análise de livros de Biologia. Segundo esses autores, a área das ilustrações referentes a Darwin é, em média, cerca de oito vezes maior que a área das figuras sobre Lamarck, em livros do período 1940-2006. Exceto pela veiculação de um retrato de Lamarck na coleção 1, as ideias lamarckistas não foram ilustradas nas obras analisadas.

\section{CONTEXTUALIZAÇÃO E ATIVIDADES}

A proposta de Batista, Mohr e Ferrari47 apresenta um descritor sobre os tipos de contextualização que podem ser aliados à contextualização histórica, com as seguintes categorias: social, política e religiosa. Elas possuem títulos autoexplicativos e, em nosso corpus, verificou-se apenas a

\footnotetext{
44 Cláudia Kamel \& Lucia Rodriguez de La Rocque, "As Histórias em Quadrinhos como Linguagem Fomentadora de Reflexões: Uma Análise de Coleções de Livros Didáticos de Ciências Naturais do Ensino Fundamental." Revista Brasileira de Pesquisa em Educação em Ciências 6, no 3 (2006): 7. 45 Martins, Gouvêa \& Vilanova.

46 Almeida \& Falcão, "As Teorias de Lamarck e Darwin".

47 Batista, Mohr \& Ferrari.
} 
categoria social, referente a aspectos gerais da sociedade à época do desenvolvimento dos fatos históricos sobre evolução. Esse tipo de contextualização, nas obras analisadas, ocorre por meio da apresentação de textos entremeados aos conteúdos, na forma de boxes e seções específicas, ou na forma de atividades.

A coleção 1 sugere ao professor levantar com os alunos dados a respeito da composição étnica dos moradores de Galápagos e os costumes da região, propondo-se a seguir a elaboração de uma feira cultural. Propõe-se também, como complemento de estudos ao professor, pesquisar a passagem de Darwin pelo Brasil e suas impressões a respeito da escravidão. Mais à frente são apresentados os textos intitulados "Raças humanas?" e "Darwinismo social". Já na coleção 2, há uma seção nomeada "Ciências e sociedade". Nela, o texto "Variedade dos seres vivos" comenta a importância de se respeitar os costumes, tradições e conhecimentos que os povos adquirem e passam para as gerações seguintes. Por fim, na coleção 3 levanta-se o conceito de ancestralidade, sugerido ao professor com 0 intuito de tornar os estudos em evolução mais interdisciplinares.

Portanto, não foram abordadas formas de contextualização política nem religiosa nas obras analisadas. Deve-se considerar a importância desses itens para a humanização da ciência. Cientistas não estão isentos de preferências em termos de política e religião, que podem influenciar seus trabalhos. Darwin, por exemplo, estudou teologia antes de escrever sobre suas teorias, que mais tarde iriam se chocar com o conceito de criação divina. Também não se trata de defender que os livros concedam tanto espaço a crenças não validadas cientificamente, o que feriria o caráter laico da educação pública preocupação externada Tomotani e Salvador ${ }^{48}$, que analisaram o tema da evolução em livros da edição de 2014 do PNLD-Ciências:

[...] o conteúdo religioso dos livros precisa ser analisado mais a fundo para se determinar a proporção de livros (tanto os listados pelo PNLD quanto os demais) em que o Criacionismo está presente e: (1) se ele é apresentado como alternativa válida à Evolução (e, portanto, à Ciência) ou (2) se a religião é abordada somente para evitar ofender grupos de grande força política (essa tentativa de agradar gregos e troianos é vista nos Estados Unidos).

48 João V. Tomotani \& Rodrigo B. Salvador, "Análise do Conteúdo Evolução em Livros Didáticos do Ensino Fundamental Brasileiro.' Pesquisa e Ensino de Ciências Exatas e da Natureza 1, no 1 (2017): 15. 
Entendemos que a educação pública não pode, em qualquer hipótese, se fiar a esse tipo de relativismo. As incertezas da ciência não justificam que os livros adotem formas extremas de pluralismo epistemológico, como bem apontam Bizzo, Chassot e Arantes ${ }^{49}$ :

Seria um absurdo um criacionista dizer: "Bem, como os astrônomos estão em dúvida sobre como se formou o universo, então não podemos considerar que o sistema solar seja heliocêntrico; ensinemos também o geocentrismo". Isso parece uma piada, mas é exatamente o que se passa no contexto biológico. A incerteza científica é apresentada como ausência de consensos mínimos sobre formas de explicar a realidade. Sofisma, diriam os mais cândidos; cinismo puro, diriam outros; impostura intelectual com fins escusos, diriam os mais exaltados.

Por outro lado, e como já afirmamos, tais formas de contextualização também não precisam servir ao ataque ou à deslegitimação das crenças que os alunos já trazem à escola. Considerando o perfil conceitual de adaptação, e especificamente as zonas do funcionalismo intra-orgânico e do ajuste providencial - com compromissos ontológicos mais sujeitos à influência espiritual ${ }^{50}$-, a contextualização religiosa pode ser importante não só para esclarecer aspectos da constituição histórica do conceito darwinista de adaptação, mas também para tornar os estudantes mais conscientes de seu próprio perfil conceitual, compreendendo os âmbitos de aplicação e validade de cada zona que o compõe. Essa autoconsciência, inclusive, é um dos aspectos que diferenciam aprendizagem segundo os perfis conceituais das antigas propostas de mudança conceitual ${ }^{51}$.

Com relação aos tipos de atividade, algumas já foram comentadas, e descreveremos brevemente outras mais. Como mostra 0 Quadro 1, esse descritor abrange cinco categorias: leitura no próprio livro, leitura em outras fontes, pesquisa bibliográfica, análise de dados históricos e experimentos históricos. Apenas a coleção 2 não contemplou a maioria delas.

A coleção 1 procura expandir-se discursivamente ao propor leituras de fontes on-line, seguindo uma tendência observada em outros livros didáticos brasileiros de ciências ${ }^{52}$. Além disso, podemos considerar presentes, grosso modo, as categorias análise de dados históricos e experimentos históricos, graças a atividades relacionadas à diversidade dos bicos das aves, aos mecanismos de seleção natural e

\footnotetext{
49 Nélio M. V. Bizzo, Attico Chassot \& Valéria A. Arantes, orgs., Ensino de Ciências: Pontos e Contrapontos (São Paulo: Summus, 2013), 143.

50 Sepulveda, Mortimer \& El-Hani.

51 Eduardo F. Mortimer, Linguagem e Formação de Conceitos no Ensino de Ciências (Belo Horizonte: UFMG, 2000).

52 Garcia.
} 
a evidências fósseis de animais a serem comparadas com cavalos atuais. Recursos semelhantes aparecem na coleção 2, que propõe uma atividade prática sobre formação de fósseis utilizando massa de modelar. Nesse descritor, apenas a coleção 3 contempla todas as categorias, com destaque para a presença de experimentos históricos no manual do professor, com as práticas "Camuflagem e seleção natural" e "Simulando a formação de fósseis".

\section{CONSIDERAÇÕES FINAIS}

As análises aqui realizadas confirmaram, em parte, resultados de outros estudos sobre o tema evolução em livros didáticos brasileiros ${ }^{53,54,55}$.

A evolução é apresentada de forma concentrada em um dos volumes da coleção, normalmente aquele destinado ao $7^{\circ}$ ano. Ainda, a abordagem histórica do tema está presente, conforme orientam documentos curriculares oficiais, mas de forma adaptada - o que favorece, senão erros conceituais graves, ao menos imprecisões e omissões.

Entre os nomes de Darwin, Lamarck, Wallace e Lyell, é o autor de A origem das espécies quem mais recebe atenção por parte das obras escolares, dando continuidade a uma tradição do ensino de evolução já bastante antiga. Nessa tradição, a teoria da seleção natural é tratada como epítome de abordagem científica do problema da evolução, contraposta às leis de Lamarck. Tomotani e Salvador ${ }^{56}$, em suas análises de livros de Ciências, consideram positiva a dedicação de pouco espaço às contribuições lamarckistas para a teoria da evolução. Para os autores, menos menções a Lamarck geram menos confusões na abordagem do tema. À luz das atuais discussões sobre a incorporação da história da ciência a conteúdos da educação científica escolar, não concordamos plenamente com essa posição. № limite, ela pode conduzir ou à defesa da exclusão da contextualização histórica, ou ao silenciamento do aspecto coletivo da produção do conhecimento, dado que as ideias de Lamarck foram importantes para os trabalhos de Darwin.

Quanto aos recursos empregados para viabilizar a abordagem histórica do ensino de evolução, observamos que eles podem proporcionar um ensino que valorize a construção da zona variacional do perfil conceitual de adaptação. Não foram observadas, nos livros, tentativas de desqualificar ou confrontar as visões mais associadas a outras zonas do perfil, especialmente as zonas do funcionalismo intra-

\footnotetext{
53 Almeida \& Falcão, "As Teorias de Lamarck e Darwin".

54 Caroline Badzinski \& Erica E. S. Hermel, "A Representação da Genética e da Evolução Através de Imagens Utilizadas em Livros Didáticos de Biologia." Ensaio: Pesquisa em Educação em Ciências 17, no 2 (2015): 434-454.

55 Tomotani \& Salvador.

56 Ibid.
} 
orgânico e do ajuste providencial. Isso indica que a atual produção de livros escolares brasileiros parece ter superado aqueles modelos de aprendizagem que já não respondem às características do público escolar contemporâneo, especialmente o modelo de mudança conceitual.

Perspectivas futuras, para a continuidade destes estudos, incluem a análise do conjunto completo de coleções do PNLD/2017-Ciências (e outras edições mais recentes do programa), assim como investigações mais aprofundadas sobre os recursos aqui analisados de forma breve, como as ilustrações (preferencialmente, por meio de referenciais inspirados na semiótica), as formas de contextualização aliadas à contextualização histórica e as atividades propostas.

\section{SOBRE OS AUTORES:}

Jessica Amanda Lourenço dos Santos

Universidade Federal do ABC

amanda.lourenco@ufabc.edu.br

Gabriel Nardy Klein

Escola Estadual Júlio Dinis

gabrielnardyk@gmail.com

Waldir Stefano

Universidade Presbiteriana Mackenzie

waldir.stefano@mackenzie.br

Rafael Cava Mori

Centro de Ciências Naturais e Humanas, Universidade Federal do ABC

rafael.mori@ufabc.edu.br

Artigo recebido em 09 de março de 2020 Aceito para publicação em 25 de maio de 2020 